This item was submitted to Loughborough's Institutional Repository (https://dspace.lboro.ac.uk/) by the author and is made available under the following Creative Commons Licence conditions.

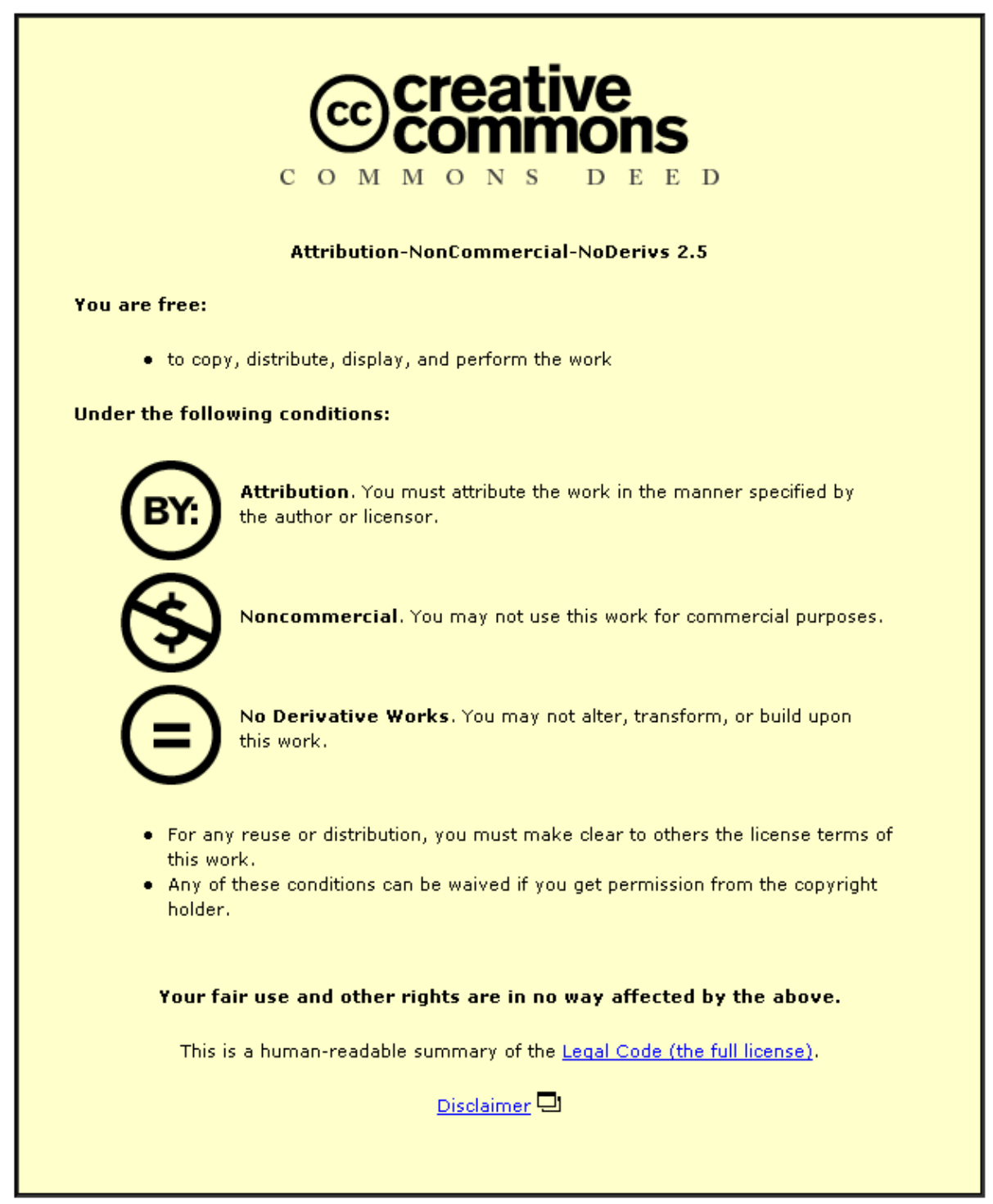

For the full text of this licence, please go to: http://creativecommons.org/licenses/by-nc-nd/2.5/ 


\title{
EFFECT OF SHADING CAUSED BY DUST ON CADMIUM TELLURIDE PHOTOVOLTAIC MODULES
}

\author{
H. Qasem*, T.R. Betts and R. Gottschalg. \\ Centre for Renewable Energy Systems Technology (CREST), Department of Electronic and Electrical Engineering, \\ Loughborough University, Leicestershire, LE11 3TU, UK. \\ *Phone: +44(0)1509 63 5337, Fax: +44(0)1509 635301 E-mail: H.Qasem@lboro.ac.uk
}

\begin{abstract}
The effect of dust on Cadmium-Telluride photovoltaic (PV) thin film modules is investigated by the application of a spatial 3 dimensional model developed with the circuit analysis software PSPICE. The effect of dust concentration and tilt angle variation on the PV module's performance was investigated. The probability of hotspots in different installation positions is investigated. The simulation results showed a reduction in the sample's performance with increased dust concentration and reduced tilt angle. The variation between cell positions showed that a horizontal orientation of the cells has an increased risk of hotspots with cells with localized lower parallel resistances than cells identified with uniform high parallel resistance.
\end{abstract}

\section{INTRODUCTION}

The high initial cost of PV systems requires governmental incentives that are typically being paid in form of a tariff. These subsidies are essential factors as the system will payback its capital cost over a period of time and then generate a surplus. Module manufacturers tend to guarantee module power reductions of less than $10 \%$ in the first 10 years, and less than $20 \%$ for the next $20-25$ years for crystalline Silicon technologies, which promoted PV systems to become a very attractive source of energy $[1,2]$, provided that all components work well. Unfortunately, there are many external factors that can limit device performance. Those factors are not included in the test procedures used to determine the PV module lifetime performance. One of the factors is quasi-continuous cell mismatch due to manufacturing defects and natural soiling such as bird droppings, snow, pollutants and dust. The latter is the focus of this paper.

In most arid zones of the world, sand dust is a detrimental agent as far as solar energy applications are concerned. When foreign particles fall on PV modules, they interfere with illumination quality by both absorbing and scattering light. The degree to which the particles interfere depends on their constitution, density, and size distribution [3]. The accumulation of dust on the PV module's surface area can produce spots with varying concentrations of dust particles, as illustrated in Figure 1. These spots vary in shape, location and concentration density. The variation in dust accumulation in any place can lead to different transmittance of light into the module, thus leading to small random areas on the PV module with less exposure to solar radiation. This effect is equivalent to inhomogeneous shading on the surface of the module. It also increases the possibility to trigger the hot spot effect where the operating current of a module exceeds the short circuit current of the worst affected cell, e.g. due to shading or dust accumulation [4-6]. When this case occurs, the affected cells are forced into reverse bias and thus dissipate power.
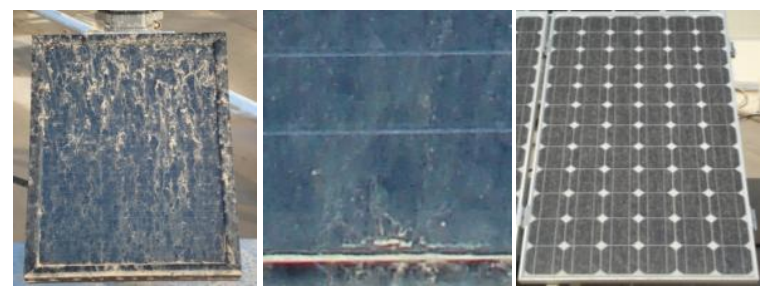

Figure 1: Accumulated dust on PV modules installed in Kuwait, from the left, CIGS, CIGS close up picture and mono-crystalline.

Of the currently available technologies, the behavior of those with the largest market share, such as mono and poly crystalline silicon is well understood. The PV module is protected through the use of bypass diodes across a substring of several cells. Thin film devices, such as amorphous Silicon (a-Si) and Cadmium Telluride (CdTe), are more vulnerable to this problem [7-8]. This is due to the construction method of these modules and the fact that most of them have their cells connected in series, making them more vulnerable to shading. Also, because of the way thin film modules are fabricated, it does not allow for cell sorting and control during the manufacturing process because the materials are directly deposited on the module substrate.

Some manufacturers claim that thin film technologies are less vulnerable to shading if they are installed with their cells oriented vertically to the plane as illustrated in Figure 2. The reason is that the probability of a cell being fully shaded is reduced and only a portion of the cell will be exposed to shading, which may not affect the module output greatly [1]. This claim, though holding true in some cases, does not take into consideration that triggered hot spot due to shading does not necessarily occur when a cell is fully shaded, but can happen when a cell, or group of cells, are partially shaded [4-6, 9]. In the long term, that will not only affect the performance of the module, it may lead to unrecoverable damage to the cell due to hot spot overheating. 


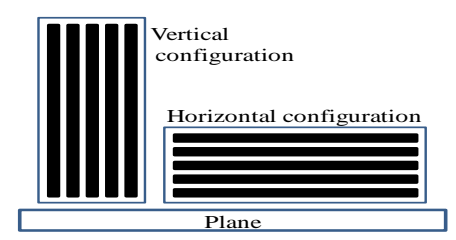

Figure 2: Horizontal and vertical orientation configuration.

In this paper the focus is on thin film technology, especially CdTe modules. A Spatial 3 Dimensional Model (S3DM) is developed and used to investigate various scenarios seen in realistic outdoor operation. The effect of dust is modeled using dust density values obtained in a previous work [8], where a relation was determined between dust density and accumulation on different tilt angles.

\section{MODELLING STRUCTURE AND SPATIAL 3 DIMENSIONAL MODEL}

Dust is one of the natural elements abundant in the environment. The variation in dust particle size and composition depends on the location [10]. In some regions, dusty weather conditions tend to be more severe than in others. For example, in Kuwait dust is present in $27 \%$ of the day time throughout May to August. This results in a combination of hot and dusty weather for PV technology [11], which will be particularly challenging. Furthermore, dust tends to settle on surfaces, creating a fine layer across any exposed surface. The accumulation of dust is influence by factors such as gravitational forces, wind speed, wind direction, electrostatic charges and the wetness of the surface [13]. Out of those parameters, the most dominating effects are the gravitational effect, particle size and wind speed and direction. Slow wind will increase the deposition of dust, while fast wind speed will help remove dust of certain particle sizes if the wind is incident in an appropriate direction [12-14].

It has been reported that falling dust has a direct effect in reducing the performance of solar modules [14-19]. Accumulated and airborne dust reduces the amount of solar radiation falling on the surface of a PV module [18]. Goosens and Van Kerschaever provided a relation between airborne dust, accumulated dust and the reduction in PV cell short circuit current [19] Using a wind tunnel experiment, they showed that there is an aerodynamic relation between airborne dust, accumulated dust and the reduction in PV power output. Others reported a relation between dust particle size, particle distribution, tilt angle and the reduction in transmittance of solar radiation [3, 10, 13, 15]. In general, the literature agrees on a reduction in short circuit current with increase in accumulated dust density.

Different dust density values on glass samples tilted at different angles were reported by Qasem et al., see Table 1 [8]. In this paper, those values are used in the S3DM to investigate the effect of dust on the distribution of current through different layers within the PV cell. This effect is shown in the form of power dissipated through the cell materials.
Table 1: Dust density $\left(\mathrm{mg} / \mathrm{cm}^{2}\right)$ values for dust accumulation at different areas on a tilted surface. In the table $B=$ bottom, $\mathrm{M}=$ middle and $\mathrm{T}=$ top

\begin{tabular}{cccccccccc}
\hline & & $\mathbf{0}$ & & & $\mathbf{1 5}$ & & & $\mathbf{3 0}$ & \\
\hline & $\mathbf{B}$ & $\mathbf{M}$ & $\mathbf{T}$ & $\mathbf{B}$ & $\mathbf{M}$ & $\mathbf{T}$ & $\mathbf{B}$ & $\mathbf{M}$ & $\mathbf{T}$ \\
AVG & 7.1 & 6.0 & 6.9 & 4.9 & 4.2 & 4.8 & 5.4 & 3.6 & 2.6 \\
MIN & 8.5 & 7.7 & 7.8 & 6.2 & 5.6 & 6.1 & 6.7 & 4.9 & 3.8 \\
MAX & 6.4 & 5.2 & 6.5 & 4.0 & 3.6 & 4.3 & 4.9 & 3.0 & 2.1 \\
STD & 0.5 & 0.6 & 0.3 & 0.6 & 0.5 & 0.4 & 0.4 & 0.4 & 0.4 \\
\hline & & $\mathbf{4 5}$ & & & $\mathbf{6 0}$ & & & $\mathbf{9 0}$ & \\
\hline & $\mathbf{B}$ & $\mathbf{M}$ & $\mathbf{T}$ & $\mathbf{B}$ & $\mathbf{M}$ & $\mathbf{T}$ & $\mathbf{B}$ & $\mathbf{M}$ & $\mathbf{T}$ \\
AVG & 2.3 & 2.9 & 2.6 & 2.5 & 2.5 & 2.0 & 0.6 & 0.4 & 0.4 \\
MIN & 3.3 & 4.1 & 3.8 & 3.5 & 3.4 & 3.1 & 0.9 & 0.8 & 0.7 \\
MAX & 1.8 & 2.5 & 2.2 & 2.1 & 2.1 & 1.6 & 0.1 & 0.1 & 0.1 \\
STD & 0.3 & 0.4 & 0.4 & 0.3 & 0.3 & 0.3 & 0.2 & 0.2 & 0.2 \\
\hline
\end{tabular}

The effect of dust accumulation on the surface of a PV module can be compared to random shadowing on the surface of a PV cell. This means the affected areas are not covered homogeneously. To better understand the effect of randomly distributed shadowing on the surface of the cell, spatially resolved measurements are required.

Spatially resolved measurement and distributed analysis in solar cells is the investigation of solar cell properties or electrical PV parameters by taking into account their location (position) on the solar cell or module [20]. It has been done in the past and is generally used to investigate the influence of the distribution and variation of physical properties on overall performance and efficiency.

Spatial simulations can be done in many different ways, depending on the type of technology that needs to be simulated and the effects it needs to represent. Different models have been reported over the years. A seriesconnected 2 dimensional (2D) model was reported by Burgelman and Niemegeers for simulating CIS and CdTe module efficiencies [21]. Other models adopted different layers of PV cell to better understand the effect of each part on the performance of the whole cell [22-25]. Galina et al. reported a 3D model which accounts for the cell's transparent conductive oxide (TCO) and back sheet contacts. Others accounted for the cell dimensions in the form of calculated resistivity [20]. Vorasayan et al. reported a distributed 3 dimension model (D3DM) focussing on the idiosyncrasies of amorphous silicon technologies.

\section{A. Cadmium Telluride Solar Cell Modelling}

The starting element for the development of the spatial model was the single diode model. The usage of this model for different types of PV technologies is possible, with some modifications to accommodate for the differences in the cell technology. Since CdTe is a polycrystalline heterojunction, the standard one diode model should be applicable with only slight modification.

$$
I(V)=I_{o}\left(e^{\frac{q V_{j}}{n K T}}-1\right)+\frac{V_{j}}{R_{s h}}-I_{p h}
$$

It was reported that CdTe device I-V curves show a limiting current in the forward bias $[27,28]$. This effect can be attributed to the device structure where in the case of 
CdTe, the material layers form a Schottky barrier with the back contacts which creates the limiting effect. This allows CdTe devices to be described by having a diode in series to the series resistance in the module. The back diode is not represented as a part of the active photovoltaic material and its influence is only on the series resistance.

As shown in the modelled circuit, the back diode is reversed biased, though it does not reach break-down for normal operating conditions [26]. The reason for that is the voltage of the cell is in the magnitude of less than one volt, while a break-down voltage is in the range of several volts. The model is equivalent to the one diode model apart from the calculation of $\mathrm{V}_{\mathrm{j}}$. The back diode has to be accounted for and thus can be calculated by:

$$
\mathrm{V}_{\mathrm{j}}=\mathrm{V}-\mathrm{IR}_{\mathrm{s}}-\mathrm{V}_{\mathrm{BD}}
$$

The back diode can be modelled as a Schottky diode, and thus, the voltage across the diode is given by:

$$
\mathrm{V}_{\mathrm{BD}}=\frac{\mathrm{kT}}{\mathrm{e}} \ln \left(\frac{\mathrm{I}}{\mathrm{I}_{\mathrm{BD}}}+1\right)
$$

$\mathrm{I}_{\mathrm{BD}}$ in this equation represents the saturation current of the back diode which is exponentially dependant on the temperature. Modifying equation 1 with equation 2 to obtain:

$$
I(V)=I_{o}\left(e^{\frac{q\left(V-I R_{s}-V_{B D}\right)}{n K T}}-1\right)+\frac{V-I R_{s}-V_{B D}}{R_{s h}}-I_{p h}
$$

This is known as the backdiode model modified by Stollwerck to represent the behaviour of CdTe technology [30].

\section{B. Spatial 3 Dimensional Model}

A one dimensional model usually consists of a one diode model with additional lateral resistance $R_{\mathrm{s}, \text { Lat }}$ In our case, as shown in Figure 3, the model is made of two diodes $I_{D}$ \& $I_{\mathrm{BD}}$, photocurrent source $\mathrm{I}_{\mathrm{ph}}$, shunt resistance $\mathrm{R}_{\mathrm{sh}}$ and series resistance $R_{s}$. The shunt resistance represents the photo-generation, recombination and parasitic losses in a practical solar cell. The series resistance in this case is the bulk resistivity of the semiconductor material and is represented as $R_{s e}$ without the contribution of the contact layers resistivity.

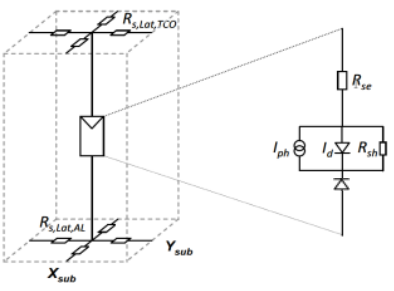

Figure 3: A single unit back diode model taking into consideration the lateral resistance $\left(R_{\text {SLa-TCO}}, R_{\text {SLa-Al }}\right)$ for the TCO and the aluminium back contacts. Also the input resistance $\left(R_{\mathrm{in}}\right)$ and $\left(R_{\mathrm{bc}}\right)$ which represent the ribbon and contact resistance were taken into consideration.
Each sub-cell is connected in parallel with each other via the $R_{\text {sLatTCO, }}$ which represents the lateral resistance of the TCO and $R_{\text {sLatAl }}$ which is the resistance of the aluminium back contacts. Each block of sub-cells is connected in series to the other cells via an input resistance $R_{\text {in }}$ which represents the monolithic contacts resistance. Other resistances present are those arising from terminal contacts $\left(R_{c}\right)$ and the ribbons at the end of module $\left(R_{b}\right)$ which are used at the model terminals. Both are represented as $\left(\mathrm{R}_{\mathrm{bc}}\right)$, a representation of the model connections is shown in Figure 4.

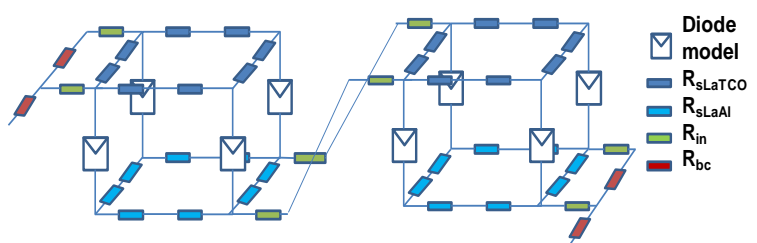

Figure 4: A representation of how S3DM blocks are connected.

Brecl et. al. reported that a variation of a distributed model with corresponding actual cell measurements exists. The variation in simulated output decreases with increasing number of sub-cells in the distributed model [28]. A CdTe cell of area $1.0 \mathrm{~cm}^{2}$ was simulated under $25^{\circ} \mathrm{C}, 1000 \mathrm{w} / \mathrm{m}^{2}$ and air mass 1.5 . The same cell was simulated, varying the number of sub-cells to $1,8,16$ and 64 . Figure 5 shows the variation between the outputs for different simulated numbers of cells.

The properties of the cell with active area divided into 4, 8 or 16 divisions differ from the properties of the cell with 64 divisions relatively by $1 \%, 0.8 \%$ and $0.2 \%$, respectively. In order to consider the distributed resistance and to keep the PSpice model accurate it was concluded that for our purpose where power dissipation in the cell will be analysed, it is sufficient to divide the model of the active solar area to 64 divisions. In comparison, increasing the cell size by an increment of $1.0 \mathrm{~cm}^{2}$ did not introduce any significant changes to the previous results obtained with $1.0 \mathrm{~cm}^{2}$ cell size.

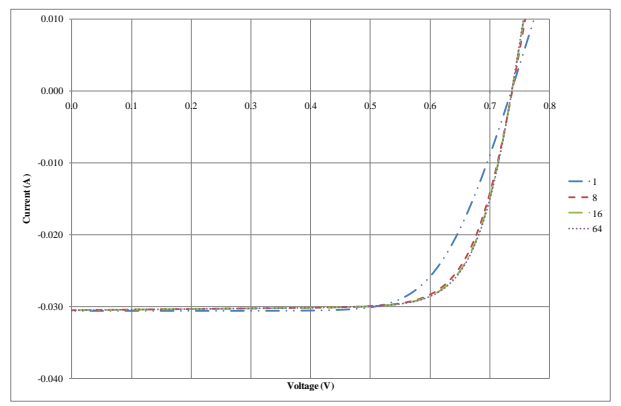

Figure 5: I-V curves for the same solar cell simulated with varying the number of distributed cells.

\section{LOSSES DUE TO THE INFLUENCE OF DUST}

Initially the effect of dust on performance is investigated with different dust concentrations. This effect was explored modelling three cells connected in series. The total area of 
the sample is $9 \mathrm{~cm}^{2}(3 \mathrm{~cm} \times 3 \mathrm{~cm})$. The sample was simulated with PSpice under $25^{\circ} \mathrm{C}, \mathrm{AM} 1.5$ and $1000 \mathrm{~W} / \mathrm{m}^{2}$. Different dust concentration values representing the effect of dust were applied by the impact of the spectral transmittance in the range $350-900 \mathrm{~nm}$ of $89.9 \%(2.3$ $\left.\mathrm{mg} / \mathrm{cm}^{2}\right), 68.9 \%\left(12.2 \mathrm{mg} / \mathrm{cm}^{2}\right), 36.5 \%\left(28.7 \mathrm{mg} / \mathrm{cm}^{2}\right)$ and $7.7 \%\left(36.7 \mathrm{mg} / \mathrm{cm}^{2}\right)$ [2]. The simulation results are shown in Table 2 and Figure 6.

The simulation showed a reduction in the power output under higher concentration of dust, where the cell performance decreased. This approach is used to simplify the effect of dust settling on the PV cell. The simplification came from the fact that dust deposition can produce complicated patterns that vary under different influences such as wind direction, particle size and gravitational effect which is represented by the tilt of the surface. In this work, only the last element was taken into consideration. The effect of gravity was represented by a gradual variation of dust on the surface of the PV cell. The simulation showed that increasing the tilt angle supports the removal of dust. This was shown by the increase in the cell output by increasing tilt angle. A high increase in the tilt angle $\left(>60^{\circ}\right)$ can reduce the effect of dust, although in most installations it is not the preferred tilt used to optimize the solar resource utilisation.

An optimized tilt, though reducing the effect of dust relative to a $0^{\circ}$ tilt, can introduce a significant variation in settled dust concentration on different areas of the module. In most cases, where no rain effect is introduced, tilting the PV module can introduce a gradual settlement of dust where higher concentration is settled at the bottom and lower concentration at the top.

This effect poses a risk of triggering hotspots in the cells. The simulated sample was divided into 4 regions where higher concentration of dust was settled in a smaller area in the bottom of the cell, while the top area, which represents the major area of the cell, has a very low dust concentration. This configuration aims to represent a scenario of a $30^{\circ}$ tilted module exposed to a very dusty climate for a short period of time. Two different variations of material variations were introduced; uniform high parallel resistance (voltage limited -VL) and localized low parallel resistance (current limited $-\mathrm{CL}$ ). The sample was simulated in two orientations, with cells oriented in a horizontal position to the plane (Hor) and vertical position (Vert) as illustrated in Figure 1. The simulations are shown in Figure 7 and Table 3.

Table 2: Simulated cell parameters under different dust scenarios normalized to the clean sample.

\begin{tabular}{ccrrrrr}
\hline & $\begin{array}{c}\text { Voc } \\
(\mathbf{V})\end{array}$ & Isc (A) & MPP (W) & Im (A) & Vm (V) & FF \\
\hline $\mathbf{3 6 . 7} \mathrm{mg} / \mathrm{cm}^{2}$ & 0.326 & 0.077 & 0.010 & 0.049 & 0.199 & 0.392 \\
$\mathbf{2 8 . 7} \mathrm{mg} / \mathrm{cm}^{2}$ & 0.908 & 0.355 & 0.205 & 0.249 & 0.823 & 0.636 \\
$\mathbf{1 2 . 2} \mathrm{mg} / \mathrm{cm}^{2}$ & 0.972 & 0.689 & 0.602 & 0.626 & 0.961 & 0.898 \\
$\mathbf{2 . 3} \mathrm{mg} / \mathrm{cm}^{2}$ & 0.995 & 0.899 & 0.869 & 0.879 & 0.989 & 0.971 \\
$0^{\circ}$ & 0.982 & 0.764 & 0.696 & 0.716 & 0.972 & 0.928 \\
$15^{\circ}$ & 0.986 & 0.824 & 0.772 & 0.785 & 0.983 & 0.951 \\
$30^{\circ}$ & 0.991 & 0.850 & 0.806 & 0.819 & 0.983 & 0.957 \\
$\mathbf{4 5}$ & 0.991 & 0.888 & 0.855 & 0.864 & 0.989 & 0.972 \\
$90^{\circ}$ & 1.000 & 0.979 & 0.973 & 0.973 & 1.000 & 0.994 \\
\hline
\end{tabular}

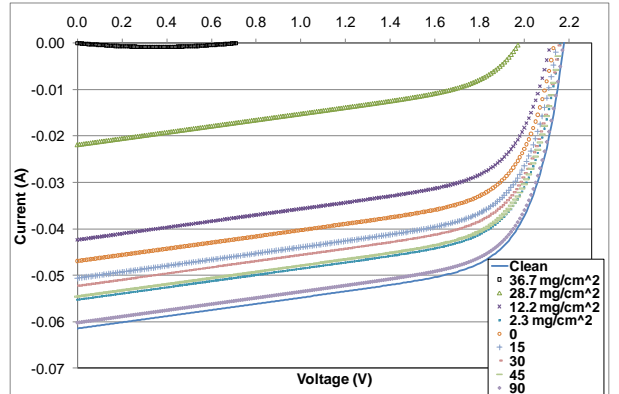

Figure 6: I-V curves for the simulated samples under different dust concentration and different tilt angles.

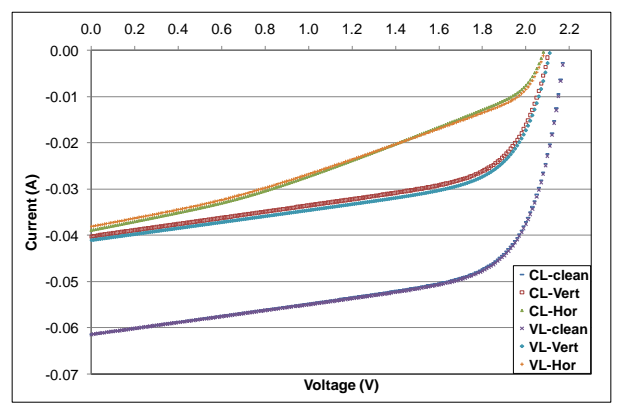

Figure 7: I-V curves for the simulated samples with different material properties.

Table 3: Simulated samples parameter values normalized to the clean samples

\begin{tabular}{lcccccc}
\hline & Voc(V) & Isc(A) & MPP (W) & Im (A) & Vm(V) & FF \\
\hline CL-Vert & 0.968 & 0.655 & 0.559 & 0.585 & 0.956 & 0.882 \\
CL-Hor & 0.959 & 0.633 & 0.337 & 0.480 & 0.702 & 0.555 \\
VL-Vert & 0.972 & 0.668 & 0.578 & 0.605 & 0.956 & 0.890 \\
VL-Hor & 0.959 & 0.620 & 0.333 & 0.459 & 0.725 & 0.559 \\
\hline
\end{tabular}

The variation types introduced a small difference (1\%) between the dust-free samples. The worst case was seen in the horizontal cells configuration, where the sample lost $66.3 \%$ of its maximum power when a current limiting cell was introduced in comparison to $66.7 \%$ for a voltage limiting cell. This can be attributed to the horizontal configuration allowing a full length of the cell to be covered by dust while the vertical configuration introduced $44.1 \%$ and $42.2 \%$ reductions for the current-limiting and voltagelimiting scenarios, respectively. The power loss in the two cell orientations varied within each module and so a detailed investigation was undertaken under maximum power point as shown in Table 4.

Table 4: Percentage power variation in the sample cell due to the high and low shunt.

\begin{tabular}{ccccccc}
\hline & CL-Clean & CL-Vert & CL-Hor & VL-clean & VL-Vert & VL-Hor \\
\hline TCO & 0.185 & 0.085 & 0.066 & 0.190 & 0.095 & 0.061 \\
BC & 0.0005 & 0.0003 & 0.0001 & 0.0005 & 0.0003 & 0.0001 \\
Rsh & 99.794 & 99.906 & 99.928 & 99.789 & 99.895 & 99.934 \\
Rse & 0.117 & 0.097 & 0.093 & 0.117 & 0.099 & 0.086 \\
Rin & 0.014 & 0.006 & 0.004 & 0.014 & 0.006 & 0.004 \\
Rbc & 0.006 & 0.003 & 0.002 & 0.006 & 0.003 & 0.002 \\
Total & 25.865 & 42.151 & 63.864 & 25.081 & 39.545 & 64.099 \\
\hline
\end{tabular}

Total power is with respect to maximum power point of the cell. 
The voltage limiting samples showed a more uniform power dissipation per cell and less uniform power dissipation between the cells than that of the non-shaded sample, see Figure 8. The effect occurred when the sample was placed in the horizontal cells configuration due to uniform shading on the first cell at the bottom (Figure 8-right). Less uniform power dissipation was observed when the voltage limited sample was simulated in the vertical cells configuration (Figure 8-bottom). This can be attributed to the lower current limiting of the cell in this configuration compared to the horizontal cell configuration. The first configuration orientation can lead to a slow and uniform heating in the shaded cells when it operates at higher current than that of the cells maximum power point.

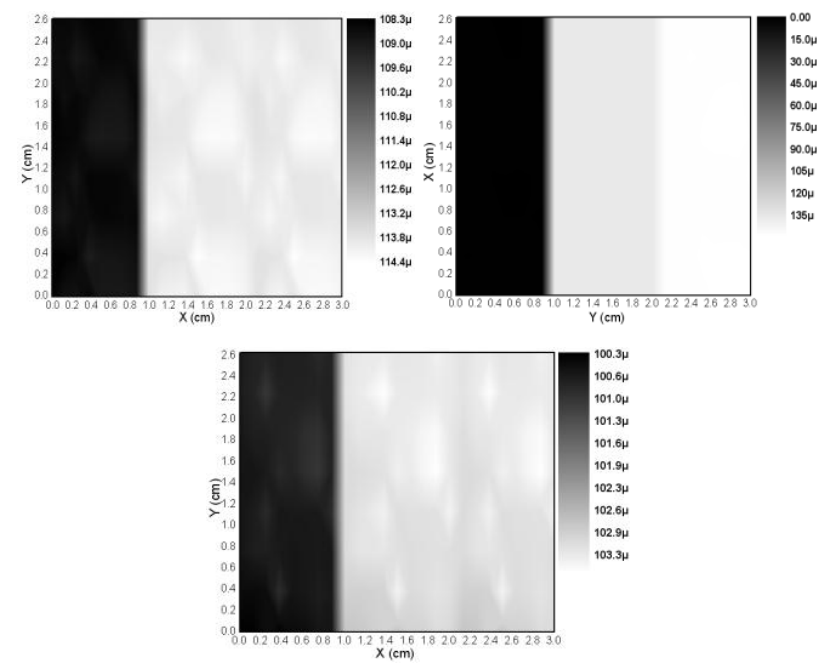

Figure 8: Voltage limited samples. From the top left, clean, dusted horizontal, dusted vertical samples. X-axis always represents the plane position. The scales on the contour maps are in watt (W).

The current limiting cell showed a more severe power dissipating area around the material variation regions as shown in Figure 9. The horizontal cell configuration showed a higher sensitivity to power dissipation around the material variation regions. On the other hand, the vertical cell configuration did not show any signs of heated hotspot. This is mainly due to the placement of the local defects in the sample with respect to the area exposed to higher dust concentration in the sample.
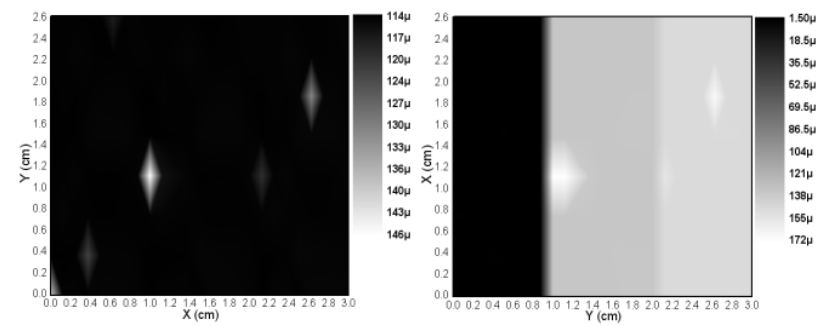

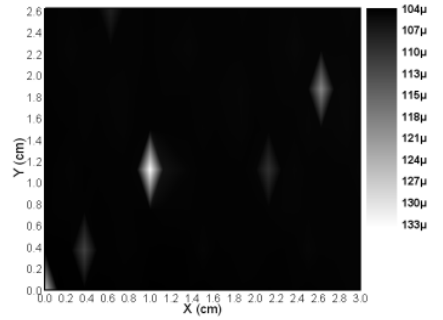

Figure 9: Current limited samples. From the top left, clean, dusted horizontal, dusted vertical samples.

Operation at maximum power point will set the operating current of the PV cell lower than the short circuit current and thus reduce the impact of the dusting. This is illustrated in Figure 10 where the same current limited sample was simulated in a horizontal cell configuration at short circuit current to introduce the worst case scenario. The heated area showed a higher value than that showed in the sample simulated operating at the maximum power point.

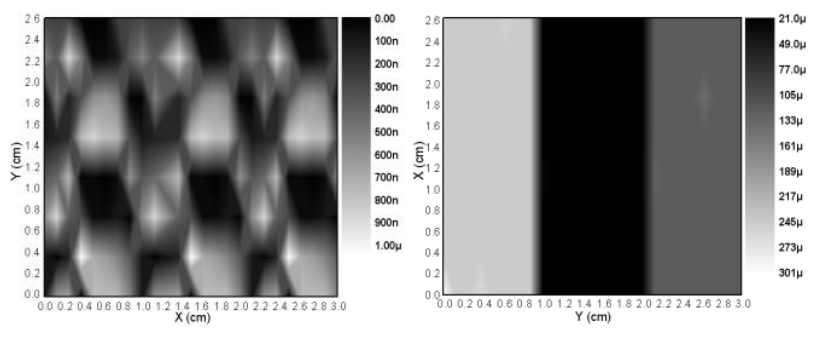

Figure 10: Variation between current limited samples at short circuit current in a horizontal configuration. From the left, clean sample and dusty sample.

\section{CONCLUSION}

The accumulation of dust on the surface of a PV module will reduce the performance with dependence on dust concentration and the module tilt angle. With increasing tilt angle the effect of dust is reduced, although it can introduce a density variation of the accumulations of dust on the surface of the module which can increase the possibility of triggering hotspots.

Simulated dust samples showed higher reduction in power when the PV module is installed in a configuration where the cells are oriented in the horizontal. This gives a higher dust concentration at the bottom cell, reducing the power of the module by $66.7 \%$ for a voltage limiting cell and $66.3 \%$ for a current limiting cell in comparison to $42.2 \%$ and $44.1 \%$ respectively for a vertical cell configuration.

PV cells identified with localized low parallel resistance and uniform high parallel resistance are more vulnerable to hotspots in horizontal cell configuration at normal operating conditions. On the other hand, PV cells identified with higher parallel and lower parallel resistance are less vulnerable to uniform hotspot heating when exposed to dust at vertical cell configurations. Cells identified with localized lower parallel resistance tend to be more vulnerable to hotspots in the horizontal configuration 
than that of cells identified with higher uniform parallel resistance. This is mainly due to the fact fully shaded cells are required to overheat cells identified localized lower parallel resistance.

\section{REFERENCES}

[1] Deutsche Gesellshaft Fur Sonnenenergie, Planning and Installing Photovoltaic Systemsa Guide for Installers, Architects and Engineers. London: Earthscan, 2008.

[2] European Photovoltaic Industry Association. (2010, 4/2010). EPIA. 2010(15/9/2010), pp. 16.

[3] A. Y. Al-Hasan, "A new correlation for direct beam solar radiation received by photovoltaic panel with sand dust accumulated on its surface," Solar Energy, vol. 63, pp. 323-333, 11, 1998.

[4] Standard test method for hot spot protection testing of photovoltaic modules, ASTM Standard, E2481-08, 2006.

[5] Standard for flat-plate photovoltaic modules and panels, UL Standard, 1703, 2002.

[6] Thin-film terrestrial photovoltaic (PV) modules - design qualification and type approval, IEC Standard, 61646, 2008.

[7] F. Antony, Photovoltaics for Professionalssolar Electric Systems Marketing, Design and Installation. Berlin: Solarpraxis AG, 2007.

[8] H. Qasem, T. R. Betts, H. Muellejans, H. AlBusairi, R. Gottschalg. "Dust effect on PV modules," In $7^{\text {th }}$ Photovoltaic Science Application and Technology Conference, Edinburgh, 2011.

[9] M. C. A. Garcia, W. Herrmann, W. Bohmer and B. Proisy, "Thermal and electrical effects caused by outdoor hot-spot testing in associations of photovoltaic cells," Prog. Photovoltaics, vol. 11, pp. 293-307, AUG, 2003.

[10] S. Biryukov, "An experimental study of the dry deposition mechanism for airborne dust," J. Aerosol Sci., vol. 29, pp. 129-139, 2, 1998.

[11] M. I. Safar and Kuwait. Meteorological Dept., Dust and Duststorms in Kuwait. Kuwait: State of Kuwait, Directorate General of Civil Aviation, Meteorological Dept., 1980.

[12] M. Mani and R. Pillai, "Impact of dust on solar photovoltaic (PV) performance: Research status, challenges and recommendations," Renewable and Sustainable Energy Reviews, vol. 14, pp. 3124-3131, 12, 2010.

[13] M. S. El-Shobokshy and F. M. Hussein, "Effect of dust with different physical properties on the performance of photovoltaic cells," Solar Energy, vol. 51, pp. 505-511, 12, 1993.

[14] D. Goossens and E. Van Kerschaever, "Aeolian dust deposition on photovoltaic solar cells: the effects of wind velocity and airborne dust concentration on cell performance," Solar Energy, vol. 66, pp. 277-289, 7, 1999.

[15] E. Asl-Soleimani, S. Farhangi and M. S. Zabihi, "The effect of tilt angle, air pollution on performance of photovoltaic systems in Tehran," Renewable Energy, vol. 24, pp. 459-468, 11, 2001.
[16] H. Pang, J. Close and K. Lam, "Study on Effect of Urban Pollution to Performance of Commercial Copper Indium Diselenide Module,." in IEEE $4^{\text {th }}$ world Conf. on Photovoltaic Energy Conversion, Waikoloa, HI,2007,pp. 2195 - 2198.

[17] M. S. El-Shobokshy and F. M. Hussein, "Degradation of photovoltaic cell performance due to dust deposition on to its surface," Renewable Energy, vol. 3, pp. 585-590, 10, 1993.

[18] H. K. Elminir, A. E. Ghitas, R. H. Hamid, F. ElHussainy, M. M. Beheary and K. M. Abdel-Moneim, "Effect of dust on the transparent cover of solar collectors," Energy Conversion and Management, vol. 47, pp. 31923203, 11, 2006.

[19] D. Goossens, Z. Y. Offer and A. Zangvil, "Wind tunnel experiments and field investigations of eolian dust deposition on photovoltaic solar collectors," Solar Energy, vol. 50, pp. 75-84, 1, 1993.

[20] P. Vorasayan, T. R. Betts and R. Gottschalg, "Spatially distributed model for the analysis of laser beam induced current (LBIC) measurements of thin film silicon solar modules," Solar Energy Mater. Solar Cells, vol. 95, pp. 111-114, 1, 2011.

[21] M. Burgelman and A. Niemegeers, "Calculation of CIS and CdTe module efficiencies," Solar Energy Mater. Solar Cells, vol. 51, pp. 145-153, 1998.

[22] G. T. Koishiyev, "Effect of weak diodes on the performance of CdTe thin-film modules," in $34^{\text {th }}$ IEEE photovoltaic specialists conference, Philadelphia, PA., 2009, pp. 79-82.

[23] U. Rau, "Resistive limitations to spatially inhomogeneous electronic losses in solar cells," Applied Physics Letters., vol. 85, pp. 6010, 2004.

[24] P. O. Grabitz, "Modeling of spatially inhomogeneous solar cells by a multi-diode approach," Physica Status Solidi A-Applications and Materials Scienice, vol. 202, pp. 2920-2927, 2005

[25] J. R. Sites, G. T. Koishiyev and M. Topic, "Impact of local non-uniformities on thin-film PV (Invited Paper) [7409-26]," Proceeding-SPIE the international society for optical engineering, 2009.

[26] A. Niemegeers and M. Burgelman, "Effects of the $\mathrm{Au} / \mathrm{CdTe}$ back contact on IV and CV characteristics of $\mathrm{Au} /$ CdTe/CdS/TCO solar cells," J. Appl. Phys., vol. 81, pp. 2881-2886, 1997.

[27] G. Stollwerck and J. R. Sites, "Analysis of CdTe BackContact Barriers," EUROPEAN PHOTOVOLTAIC SOLAR ENERGY CONFERENCE, pp. 2020-2022, 1995.

[28] K. Brecl, "A detailed study of monolithic contacts and electrical losses in a large-area thin-film module," Progress in photovoltaics, vol. 13, pp. 297-310, 2005. 